\title{
ALTERATION OF PELVIC PARAMETERS IN ADJACENT SEGMENT DEGENERATION
}

\author{
ALTERAÇÃO DOS PARÂMETROS PÉLVICOS EM DEGENERAÇÃO DO SEGMENTO ADJACENTE \\ ALTERACIÓN DE LOS PARÁMETROS PÉLVICOS EN DEGENERACIÓN DEL SEGMENTO ADYACENTE \\ Carla lisette García Ramos ${ }^{1}$, Alejandro Reyes Sánchez ${ }^{1}$ \\ 1. Instituto Nacional de Rehabilitación. Mexico City, Mexico.
}

\begin{abstract}
Objective: To describe the changes in the spino-pelvic parameters obtained after lumbar spine surgery. Methods: Prospective study. Results: The post-surgical pelvic parameters were found as follows: pelvic incidence of $75.75^{\circ}$, sacral slope $46.18^{\circ}$, pelvic tilt $19.68^{\circ}$. The sagittal balance was $30.93 \mathrm{~mm}$, the postoperative lordosis was $66.06^{\circ}$. The surgery has significant effects on the patient's pain and posture. In our analysis, in a 12-month follow-up, we found: four patients (8.8\%, two males and two females) with degeneration of the adjacent segment according to the criteria, and there was no degeneration of the underlying segment, nor any relationship with the spino-pelvic parameters. Conclusions: The degeneration of the adjacent segment does not correlate with the pelvic parameters. Level of Evidence II, Prognostic studies. Investigation of the effect of characteristics of a patient on the outcome of the disease.
\end{abstract}

Keywords: Intervertebral disc degeneration; Magnetic resonance; Postural balance.

RESUMO

Objetivo: Descrever os câmbios nos parâmetros espino pélvicos obtidos posteriormente a cirurgia da coluna lombar. Métodos Estudo prospectivo. Resultado Os parâmetros pélvicos pós-cirúrgicos foram encontrados da seguinte forma: incidência pélvica de 75,75 graus, a inclinação sacra foi de 46,18 , a inclinação da pélvica foi de 19,68. O equilíbrio sagital foi de 30,93 mm, a lordose pós-operatória foi de $66,06^{\circ}$. A cirurgia tem efeitos significativos sobre a dor e a postura do paciente. Em nossa análise em um seguimento de 12 meses, encontramos: quatro pacientes (8,8\% do total) com degeneração do segmento adjacente de acordo com os critérios (duas mulheres e dois homens); e não houve degeneração do segmento subjacente, nem uma relação com os parâmetros spinelópicos. Conclusão: a degeneração do segmento adjacente não se correlaciona com os parâmetros pélvicos. Nível de Evidencia; II. Estudos prognósticos. Investigação do efeito das características de um paciente sobre o desfecho da doença

Descritores: Degeneração do disco intervertebral; Ressonância magnética; Equilibrio postural.

\section{RESUMEN}

Objetivo: Describir los cambios en los parámetros espino-pélvicos obtenidos después de la cirugía de columna lumbar. Métodos. Estudio prospectivo. Resultados: Los parámetros pélvicos postquirúrgicos se encontraron de la siguiente manera: incidencia pélvica de $75,75^{\circ}$, la inclinación sacra fue de 46,18 , la inclinación pélvica fue de 19,68 . El balance sagital fue de 30,93 mm, la lordosis postquirúrgica de $66,06^{\circ}$. La cirugía tiene efectos significativos sobre el dolor y la postura del paciente. En nuestro análisis en un seguimiento de 12 meses encontramos: cuatro pacientes (8,8\%, dos mujeres y dos hombres) con degeneración del segmento adyacente según los criterios y no se observó degeneración del segmento infrayacente, ni relación con los parámetros espino-pélvicos. Conclusiones: La degeneración del segmento adyacente no se correlaciona con los parámetros pélvicos. Nivel de Evidencia II; Estudios pronósticos. Investigación del efecto de características de un paciente sobre el desenlace de la enfermedad.

Descriptores: Degeneración del disco intervertebral; Resonancia magnética; Balance postural.

\section{INTRODUCTION}

The intervertebral discs are avascular structures that are found between the vertebral bodies. ${ }^{1}$ The disc bears forces of compression, flexion, and torsion; as the force applied at this level increases, the hydration of the disk and the rate of fluid expression decrease, causing rigidity of the anulus fibrosus and morphological changes to it, such as fissures, loss of disc weight, hypertrophy of the posterior elements, and the formation of osteophytes.

Adjacent segment degeneration (ASD) is defined as the disc generation that occurs in the mobile segments above and below the fused spinal level. When arthrodesis is performed, the center of rotation of the segment is altered, increasing the stress on and mobility of the facet joints and/or the discs of the adjacent mobile segments as a result of the transfer of movement of the fused segment to the neighboring non-fused segments. ${ }^{2-5}$

Intradiscal pressure on the superior adjacent segment increases by $45 \%$ after the lumbar arthrodesis causing degeneration of the disc. There are reports of histopathological and biochemical changes nine months after surgery from modifying the load patterns. ${ }^{3}$

Currently, adjacent segment degeneration is considered to be

Study conducted at the Nacional de Rehabilitación. Mexico City, Mexico.

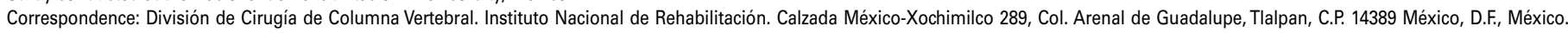
alereyes@inr.gob.mx, areyes@vertebrae.com.mx 
the result of a degenerative process and secondary to the biomechanical changes following arthrodesis of the inferior adjacent segment. Using radiographic criteria and changes in the MRI, the incidence of ASD was 8\% - 100\% (follow-up 36-369 months), while using clinical criteria, an incidence of from 5.2 - 18.5\% (44.8-164 months) was reported in patients who underwent arthrodesis. ${ }^{1,3,4}$

The risk factors for ASD are osteoporosis, age greater than 55 years, more than one fused segment, biomechanical changes, changes in laminar or facet joint inclination, preexisting disc degeneration, narrow lumbar canal, postmenopause, and obesity. ${ }^{1,3,4}$

The resulting clinical manifestations of these changes include lumbar pain, disc herniation, stenosis, spondylolisthesis, and deformity.

The earliest changes to occur in the degeneration of the adjacent segment is the loss of intravertebral disc hydration that results in a decrease in disc height. ${ }^{7}$ Biomechanical changes alter the stability of the spine, however, the degeneration of the adjacent segment has not been associated with changes in the pelvic parameters.

Spinal instability was described by Panjabi as "the loss of the ability of the spine to maintain its displacement patterns under physiological loads", 8,9 a function that is maintained thanks to the harmony of three subsystems: the spine, the muscles, and the neural control unit. The coordination of these systems is evaluated indirectly through the radiographic parameters, including the spino-pelvic parameters (Figure 1) that characterize the pelvis morphologically and functionally. These parameters are:

- Pelvic incidence. Defined by the intersection of a line drawn between the femoral heads in the middle of the sacral plateau and a line perpendicular to the middle of the sacral plateau, this angle describes the relationship between the sacrum and femoral heads and is a morphological constant. The normal values are $35^{\circ}-85^{\circ}$.

- Pelvic tilt. This is the angle between a vertical line and a line drawn from the center of the femoral heads to the middle of the upper sacral plateau.

- Sacral slope. This refers to the orientation of the sacral plateau in relation to a horizontal line. .-10 $^{-1}$

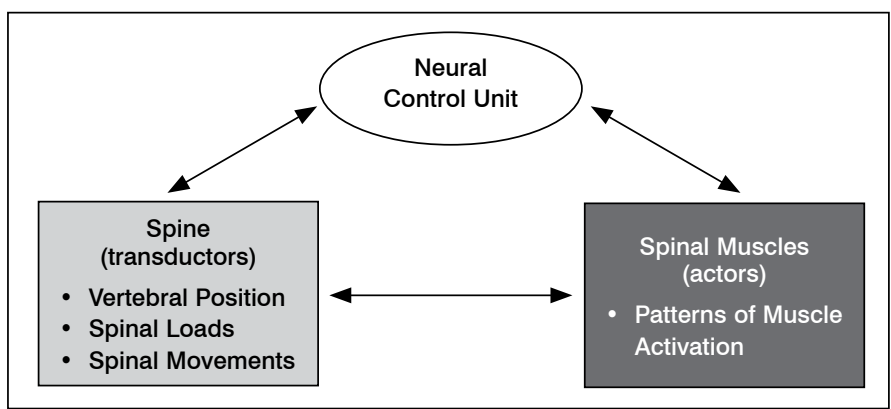

Figure 1. Spinal stability is maintained by these three systems, the failure of any of which causes spine pathologies ${ }^{9}$.

\section{OBJECTIVES}

To describe the changes in the spino-pelvic parameters obtained following surgery.

\section{METHODS}

This was a prospective study in which patients who had undergone surgery for fusion at one level (L4-L5) were evaluated postoperatively and after one year for the presence of degeneration of the adjacent disc and changes in the pelvic parameters. The study universe was comprised of patients diagnosed with degenerative L4-L5 Meyerding grade I or II spondylolisthesis, using the ICD-10 diagnostics for spondylolisthesis and degenerative spondylolisthesis (the database was obtained from the department of technology development of the in our hospital), who were treated in the spine surgery service of the in our hospital, between 49 and 75 years of age, of either sex, without previous lumbar spine surgeries, with
BMI less than 30 , with adequate bone quality (determined through densitometry), without immune or rheumatic diseases, and with a signed informed consent form for the research participants in all cases. The study was conducted after approval by the Institutional Review Board under registration number 13/15.

\section{Intervention design}

The patients who met the inclusion criteria were admitted into the study protocol and dynamic and oblique AP (anterior-posterior) and lateral radiographs of the panoramic and lumbosacral spine were analyzed in a meeting of the doctors affiliated with the spine surgery service of the INR, who decided whether the patient was a candidate for surgery. They underwent fusion of one level, after which the same measurements were repeated.

\section{Surgical intervention}

All the patients were operated by posterior lumbar approach and $360^{\circ}$ arthrodesis. After general anesthesia, the patient was placed in prone decubitus, with the hips fully extended and the lumbar approach was performed in the midline of level L4-L5, the posterior elements were dissected subperiosteally, pedicle screws were placed guided by fluoroscopy, decompression of the neural elements, discectomy, and preparation of the plateaus were performed, the PEEK (polyether ether ketone) cage filled with autologous graft was placed, proper placement was confirmed using the fluoroscope, the rods were positioned, and reduction of listhesis and compression of the screws were performed.

\section{Analysis of the images}

All the images were taken from the database of the National Rehabilitation Institute. An observer (orthopedist) took the measurements from the radiographic images with the DICOM system as follows:

- Disc height of each disc. The distance from a point at the center of the superior plateau to a point at the center of the inferior plateau of each disc from T12 to S1.

- Segmental angle. Angles between the lines that extend from the lower plateaus, measured by a Cobb angle between each segment, from T12 to S1.

- Pelvic incidence. Angle between the line perpendicular to the sacral plate and the line that joins the midpoint of the sacral plate and the bicoxofemoral axis.

- Sacral slope. Angle between the sacral plate and the horizontal plane.

- Pelvic tilt. Angle between the line that joins the midpoint of the sacral plate to the bicoxofemoral axis and the vertical plane.

- Lumbar lordosis. Angle between the superior endplate of L1 and the inferior endplate of L5.

- Sagittal balance. Drop a plumb line from C7 and measure the distance from this line to the posterior edge of the sacrum in a lateral projection of the spine.

From the magnetic resonance images of the lumbar spine taken from the DICOM system of the National Rehabilitation Institute, the degree of disc degeneration was determined by an observer using the modified Pfirrmann scale ${ }^{11}$ (Figure 2) in two separate measurements taken two weeks apart, for only the patients with degeneration at level L3-L4 of less than 5 . The radiographic and biomechanical parameters of the superior adjacent segment were correlated as a functional spinal unit.

\section{Degeneration of the adjacent segment}

The radiographic criteria taken into account to classify the appearance of degeneration of the superior adjacent segment were:

- Decrease of more than $20 \%$ in the disc height of the superior adjacent segment ${ }^{12}$.

- Listhesis of more than $3 \mathrm{~mm}$ in the neutral position radiograph.

- Angular movement of more than $10^{\circ}$ measured using the White and Panjabi ${ }^{13}$ method.

- Advance in disc degeneration in radiographs of one grade according to the UCLA classification. 


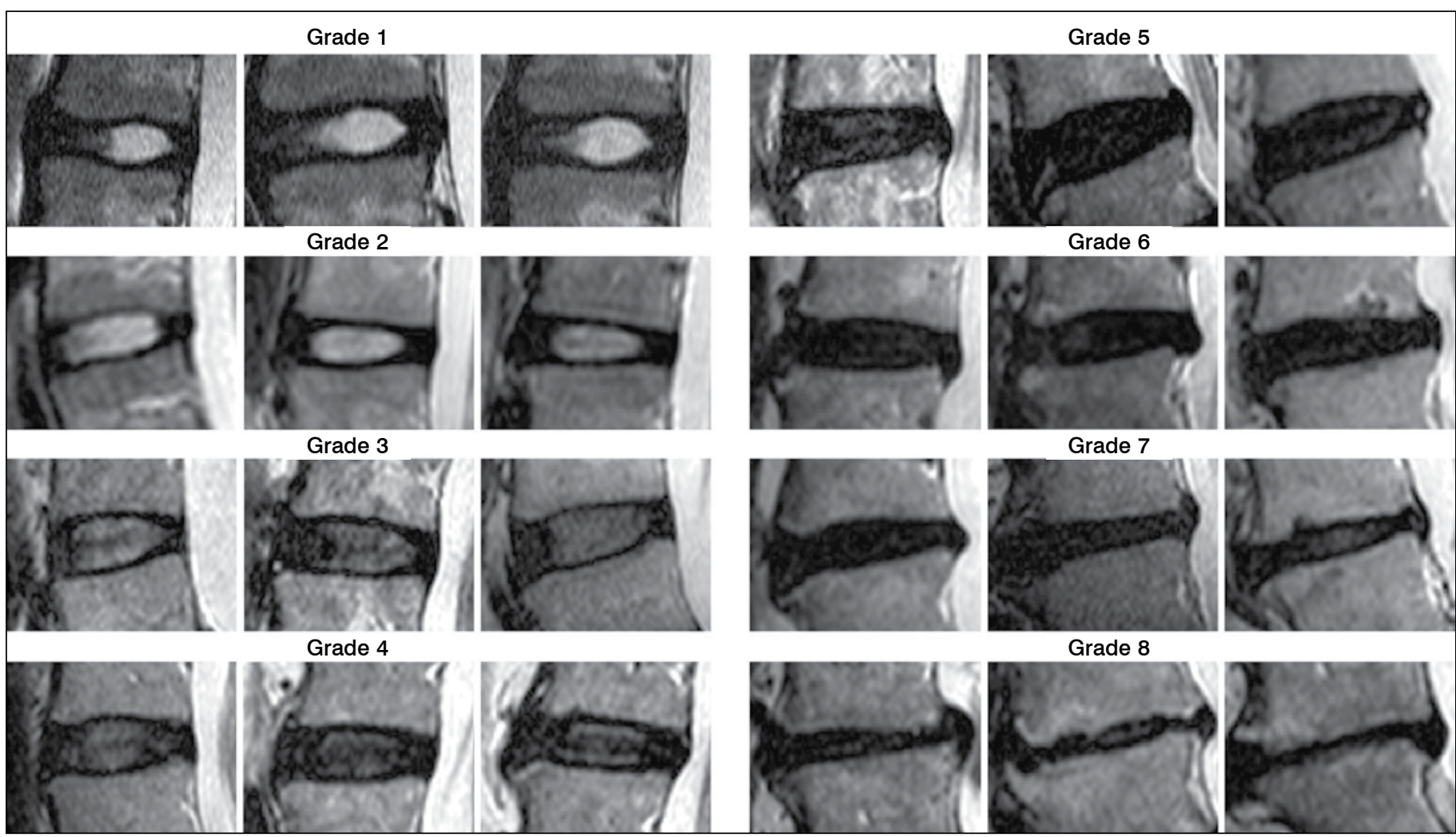

Figure 2. The modified Pfirrmann classification for disc degeneration takes changes in the intensities and the disc height into account. Grades one to four present the same height, while grades 5 to 8 present reduction of the same. Grade 1 is a normal disc and grade 8 represents total disc collapse. From reference 11.

\section{Statistical analysis}

Statistical analysis was performed with SPSS 20.0 Statistics software. Descriptive statistics were used for the quantitative variables through measures of central tendency (mean, median, and mode) and dispersion (standard deviation, maximum and minimum values and ranges). The qualitative variables were measured as percentages. A descriptive study of the parameters of the samples was conducted. For normal distribution, the means of the two groups were compared using the t test for independent samples. The chi square test was used for the qualitative variables. A value of $<0.05$ was established as a significant difference.

\section{RESULTS}

Twenty-six (57.8\%) women and nineteen (42.2\%) men participated in this study. The average age of the patients was 60.8 years (standard deviation [SD] 7.5) in an interval of 43 to 75 years. Weight ranged from $52 \mathrm{~kg}$ to $90 \mathrm{~kg}$, with an average of $66.8 \mathrm{~kg}$, and height from $1.41 \mathrm{~cm}$ to $1.79 \mathrm{~cm}$, with an average of $1.60 \mathrm{~cm}$. The average surgical time was 540 minutes. The average bleed was $396 \mathrm{ml}$, with a minimum of $70 \mathrm{ml}$ and a maximum of $1100 \mathrm{ml}$. The minimum displacement was $3 \mathrm{~mm}$ and the maximum was $19.53 \mathrm{~mm}$, with an average of $8.69 \mathrm{~mm}$ (SD $5.06 \mathrm{~mm}$ ).

Regarding pain as evaluated by the visual analog scale for pain in the total sample, an initial value of $8.06 \pm 1.1$ was obtained, which decreased after a year to $5.25 \pm 1.8$ with $p=.0001$. A significant difference between the average pre- and postoperative values of the height of $L 4-L 5$ was observed $(p=0.000)$ due to the presence of the interbody cage. In our analysis of the pelvic parameters, we found values of $p=0.001$ for pelvic incidence, $p=0.000$ for sagittal balance, $p=0.001$ for lumbar lordosis, $p=0.001$ for the T12-L1 segmental angle, in addition to a value of $p=0.001$ for preand postoperative pain, for which we concluded that the surgery had significant effects on the pain and posture of the patients. Considering the same variables for a diagnosis of degeneration of the adjacent segment used in the 2012 study by Alpizar et al. ${ }^{2}$ (decrease of more than $20 \%$ in the height of the disc of the superior adjacent level, more than $3 \mathrm{~mm}$ of translation, listhesis of more than $3 \mathrm{~mm}$ in the neutral position radiograph, angular movement of more than $10^{\circ}$ measured by the White and Panjabi method, progression of the disc generation in radiographs of one grade according to the UCLA classification), in our analysis in a 12-month follow-up we found four patients (8.8\% of the total) with adjacent segment degeneration according to the criteria (two men and two women) and we did not observe any degeneration of the inferior adjacent segment. The spino-pelvic parameters of the patients with ASD were similar to those of the patients who did not present changes in both their initial and final evaluations.

\section{DISCUSSION}

Kong et al. $^{10}$ analyzed the changes in the spino-pelvic parameters of patients with degenerative L4-L5 spondylolisthesis who underwent surgical fusion. They observed that following surgical management all the patients presented recovery of the spino-pelvic parameters and improvement of pain as measured by the visual analog scale with an average follow-up of 23.8 months. An increase in the sacral slope $\left(38.8 \pm 7.1\right.$ to $\left.43.6 \pm 7.2^{\circ}\right)$, an increase in lumbar lordosis $\left(58.0 \pm 10.4\right.$ to $\left.62.3 \pm 9.9^{\circ}\right)$, and a reduction in the angulation of the pelvic inclination $(20.2 \pm 8.3$ to $15.3 \pm 7.8^{\circ}$ ) were recorded in those patients who presented less pain following the surgery (clinical improvement was defined as a change in the visual analog scale for pain of 3 points less than the preoperative evaluation), all of them changes which were statistically significant. ${ }^{10}$

In our study, we observed changes in the spino-pelvic parameters similar to those reported by Kong: an increase of sacral slope and lumbar lordosis and a reduction of pelvic tilt, though not statistically significant. Sagittal balance remained within the normal range in all cases. 


\section{CONCLUSIONS}

Fusion of one level of the lumbar spine improves the final balance and the clinical scales. Degeneration of the adjacent segment does not correlate with the pelvic parameters.

All authors declare no potential conflict of interest related to this article.

CONTRIBUTION OF THE AUTHORS: Each author made significant individual contributions to this manuscript. GR (0000-0001-6625-6111)* and RS (0000-0002-9517-9028)* participated in the preparation of the manuscript, the review of the manuscript, and contributed to the intellectual concept of the study. GR conducted patient follow-up, collected the clinical data, and conducted the statistical analysis and the bibliographical research. ${ }^{*}$ ORCID (Open Researcher and Contributor ID).

\section{REFERENCES}

1. Fujiwara A, Lim TH, An HS, Tanaka N, Jeon CH, Andersson GB et al. The effect of disc degeneration and facet joint osteoarthritis on the segmental flexibility of the lumbar spine. Spine (Phila Pa 1976). 2000;25(23):3036-44.

2. Meyerding HW. Spondylolisthesis. Surg Gynecol Obstet.1932;54:371-7.

3. Alpizar-Aguirre A, Guevara-Álvarez A, Rosales-Olivares LM, Zarate-Kalfopulos B, SánchezBringas G, Reyes-Sánchez A. Estabilización dinámica interespinosa vs fijación transpedicular y artrodesis en el conducto lumbar estrecho de 45 a 65 años. Act Ort Mex. 2012;26(6):347-53.

4. Park P, Garton HJ, Gala VC, Hoff JT, McGillicuddy JE. Adjacent segment disease after lumbar or lumbosacral fusion: review of the literature. Spine (Phila Pa 1976). 2004;29(17):1938-44.

5. Hikata T, Kamata M, Furukawa M. Risk factors for adjacent segment disease after posterior lumbar interbody fusion and efficacy of simultaneous decompression surgery for symptomatic adjacent segment disease. J Spinal Disord Tech. 2014;27(2):70-5.

6. Dilip K, Sengupta HN. Degenerative Spondylolisthesis: review of Current Trends and Controversies. Spine (Phila Pa 1976). 2005;30(6 Suppl):S71-81.

7. Harrop JS, Youssef JA, Maltenfort M, Vorwald P, Jabbour P, Bono CM, et al. Lumbar adjacent segment degeneration and disease after arthrodesis and total disc arthroplasty. Spine (Phila Pa 1976). 2008:33(15):1701-7.

8. Roussouly P, Pinheiro-Franco JL. Biomechanical analysis of the spinopelvic organization and adaptation in pathology. Eur Spine J. 2011;20(Suppl 5):S609-18.

9. Panjabi MM. Clinical spinal instability and low back pain. $J$ of Electromyogr Kinesiol. 2003;13(4):371-9.

10. Kong LD, Zhang YZ, Wang F, Kong FL, Ding WY, Shen Y. Radiographicrestoration of sagital spinopelvica lignment after posterior lumbar interbody fusión in degenerative spondylolisthesis. Clin Spine Surg. 2016; 29(2):E87-92.

11. Griffith JF, Wang YX, Antonio GE, Choi KC, Yu A, Ahuja AT, et al. Modified Pfirrmann grading system for lumbar intervertebral disc degeneration. Spine (Phila Pa 1976). 2007;32(24):E708-12.

12. Schulte TL, Leistra F, Bullman V, Osada N, Vieth V, Marquandt B, et al. Disc height reduction in adjacent segments and clinical outcome 10 years after lumbar 360 degrees fusion. Eur Spine J. 2007;16(12): 2152-8.

13. Iguchi T, Kanemura A, Kasahara K, Kurihara A, Doita M, Yoshiya S. Age distribution of three radiologic factors for lumbar instability: probable aging process of the instability with disc degeneration. Spine (Phila Pa 1976). 2003;28(23):2628-33. 